\title{
Characterization of Phytophthora infestans Populations in Colombia: First Report of the A2 Mating Type
}

\author{
Angela M. Vargas, Lina M. Quesada Ocampo, Maria Catalina Céspedes, Natalia Carreño, Adriana González, \\ Alejandro Rojas, A. Paola Zuluaga, Kevin Myers, William E. Fry, Pedro Jiménez, Adriana J. Bernal, and Silvia Restrepo \\ First, second, third, fourth, fifth, sixth, eleventh, and twelfth authors: Laboratorio de Micología y Fitopatología, Universidad de los Andes, \\ Bogotá, Colombia; second author: Department of Plant Pathology, Michigan State University, East Lansing 48824; seventh, eighth, and \\ ninth authors: Department of Plant Pathology, 303F Plant Science, Cornell University, Ithaca, NY 14853; and tenth author: Laboratorio de \\ Fitopatología, Universidad Militar Nueva Granada, Bogotá, Colombia.
}

Accepted for publication 19 September 2008.

\begin{abstract}
Vargas, A. M., Quesada Ocampo, L. M., Céspedes, M. C., Carreño, N., González, A., Rojas, A., Zuluaga, A. P., Myers, K., Fry, W. E., Jiménez, P., Bernal, A. J., and Restrepo, S. 2009. Characterization of Phytophthora infestans populations in Colombia: First report of the A2 mating type. Phytopathology 99:82-88.

Phytophthora infestans, the causal agent of late blight in crops of the Solanaceae family, is one of the most important plant pathogens in Colombia. Not only are Solanum lycopersicum, and S. tuberosum at risk, but also several other solanaceous hosts (Physalis peruviana, $S$. betaceum, S. phureja, and $S$. quitoense) that have recently gained importance as new crops in Colombia may be at risk. Because little is known about the population structure of Phytophthora infestans in Colombia, we report here the phenotypic and molecular characterization of 97 isolates collected from these six different solanaceous plants in Colombia. All the isolates were analyzed for mating type, mitochondrial haplotypes, genotype for several microsatellites, and sequence of the internal transcribed spacer (ITS) region. This characterization identified a single individual of A2 mating type (from Physalis peruviana) for the first time

identical to the consensus sequence. Of the 97 isolates, 96 were mitochondrial haplotype IIa, with the single A2 isolate being Ia. All isolates were invariant for the microsatellites. Additionally, isolates collected from $S$. tuberosum and $P$. peruviana (64 isolates) were tested for: aggressiveness on both hosts, genotype for the isozymes (glucose-6phosphate isomerase and peptidase), and restriction fragment length polymorphism fingerprint pattern as detected by RG57. Isolates from $S$. tuberosum were preferentially pathogenic on $S$. tuberosum, and isolates from $P$. peruviana were preferentially pathogenic on $P$. peruviana. The population from these two hosts was dominated by a single clonal lineage (59 of 64 individuals assayed), previously identified from Ecuador and Peru as EC-1. This lineage was mating type A1, IIa for mitochondrial DNA, invariant for two microsatellites, and invariant for both isozymes. The remaining four $\mathrm{A} 1$ isolates were in lineages very closely related to EC-1 (named EC-1.1, CO-1, and CO-2). The remaining lineage (the A2 mating type) had characteristics of the US-8 lineage (previously identified in Mexico, the United States, and Canada). These results have important epidemiological implications for the production of these two crops in Colombia.
\end{abstract} in Colombia. All isolates had an ITS sequence that was at least $97 \%$
Late blight caused by the oomycete Phytophthora infestans is the most important disease of potato (Solanum tuberosum) worldwide. The disease was first officially reported in Colombia at the beginning of the 20th century by Toro in 1927 (35), Chardon in 1928 (8), and Chardon and Toro (9) in 1930 (see also Abad and Abad [1]). Colombia is the third-largest potato producer in South America (11) and late blight is a disease of great concern. As with most other locations in the world, control of late blight in Colombia is mainly achieved by the use of fungicides, with up to 10 applications per crop cycle. This chronic use of chemicals is not always effective and costs millions of dollars, which places an economic burden on many farmers. Consequently, the annual yields of potato and the market prices fluctuate greatly. The most desirable method of control is the use of resistant cultivars, and the search for resistance sources is a priority. Information on the pathogen population structure is a prerequisite for understanding the epidemiology of the disease and for selecting disease resistance sources for crop breeding (27).

The population structure of plant pathogens is shaped in part by reproductive strategy and host preferences $(31,34)$. Specifically,

Corresponding author: S. Restrepo; E-mail address: srestrep@uniandes.edu.co

doi:10.1094/PHYTO-99-1-0082

(C) 2009 The American Phytopathological Society sexual reproduction has been associated with higher genotypic diversity and, hence, a stronger ability to adapt to changing conditions in the crop. However, in Colombia, only the A1 mating type of $P$. infestans has been reported (16; Jaramillo, personal communications); therefore, if that situation continues, adaptation of the Colombian population to diverse changes is expected to be slower than if sexual reproduction occurred. It is feasible that A2 mating types could have been introduced, because both mating types have been detected on potato in Argentina, Bolivia, and Brazil $(4,12,14,17,34)$. In Ecuador, both mating types have been detected but there still is no evidence of sexual reproductionperhaps because of host specificity (2). In Ecuador, the A2 mating type has been found on wild species of Solanum, S. brevifolium and $S$. tetrapetalum, and on the Andean fruit crop pear melon $(S$. muricatum) whereas A1 mating types have been found on potato $(2,32,33)$. However, the situation could change there because, in 2002, A1 and A2 isolates were found on the same host pear melon (S. muricatum) (2), P. infestans is a relatively specialized pathogen, and previous studies have shown that some pathogen populations associated with different hosts show distinct genotypes $(2,4,33)$. With the exception of the isolates from $S$. muricatum, most populations in South America from a single host are clonal and contain only one mating type (32).

In addition to potato ( $S$. tuberosum and $S$. phureja) and tomato (S. lycopersicum), other members of the family Solanaceae are 
hosts to $P$. infestans and could also influence the population structure of this pathogen. Over the last decade, several species of Andean exotic fruit have become increasingly important in Colombia for both domestic consumption and the international export market (7). The most important are Physalis peruviana (cape gooseberry), a herbaceous perennial plant; $S$. betaceum (tree tomato); and $S$. quitoense (lulo or naranjilla), a perennial shrub. Each of these is a host to Phytophthora infestans $(2,3,5,10,31,36,37)$.

Except for the genotypic characterization of a very small number of isolates in the late 20th century $(13,16)$, very little is known about the population structure of $P$. infestans in Colombia. Previously, only A1 mating types had been detected $(13,16)$. It is not known if the current population is complex or simple and, if complex, the cause for the complexity is unknown. It also is not known if the population is sexual or asexual. If it is sexual, then management efforts need to be directed at oospores in the soil as well as at asexual reproduction during the season. Finally, the possibility of host specialization in this population has not been investigated. Because potato and cape gooseberry are frequently grown in close proximity, it is important to know if the population on one crop represents a serious threat to the other crop.

Therefore, the goal of this study was to determine the extent of phenotypic and genetic diversity among isolates of $P$. infestans collected from several solanaceous hosts in Colombia. To the best of our knowledge, this is the first intensive study of this pathogen in Colombia in which phenotypic and molecular approaches are combined to characterize the population structure of this important pathogen.

\section{MATERIALS AND METHODS}

Sampling and isolation of the pathogen. Samples were collected from $S$. tuberosum (potato), S. phureja (yellow potato), $S$. lycopersicum (tomato), S. betaceum (tree tomato), S. quitoense (naranjilla or lulo), and Physalis peruviana (cape gooseberry). Samplings were made during April to May and October to November 2006, corresponding to the two rainy seasons of the year in Colombia. Most of the collections were made in Cundinamarca state, which is the most important one in terms of potato and cape gooseberry production. The localities sampled in Cundinamarca were Granada, Cogua, Zipaquirá, San Raimundo, Villapinzón, Tabio, San Francisco, Tibacuy, Silvania, Fusagasugá, and Bogotá (Fig. 1A and B). Some isolates were also collected in Antioquia state (Rionegro locality). A list of the 97 isolates used in this study, including host and location of collection, is presented in Table 1.

After the A2 mating type was detected in the locality of Granada (see Results), a more intensive sampling effort during April to May 2007 was performed in eight fields close to the field in which the A2 individual was collected. In all, 100 additional strains were collected: 4 from $S$. tuberosum, 46 from $S$. phureja, 14 from $S$. lycopersicum, 8 from $S$. quitoense, 9 from $S$. betaceum, and 19 from $P$. peruviana. These strains were tested only for mating type.

Isolation into pure culture of each strain of Phytophthora infestans was carried out by transferring sporangia from sporulating lesions to rye agar media with ampicillin (200 mg/liter) and incubating the culture at $18^{\circ} \mathrm{C}$ for 8 days in the dark (19). For

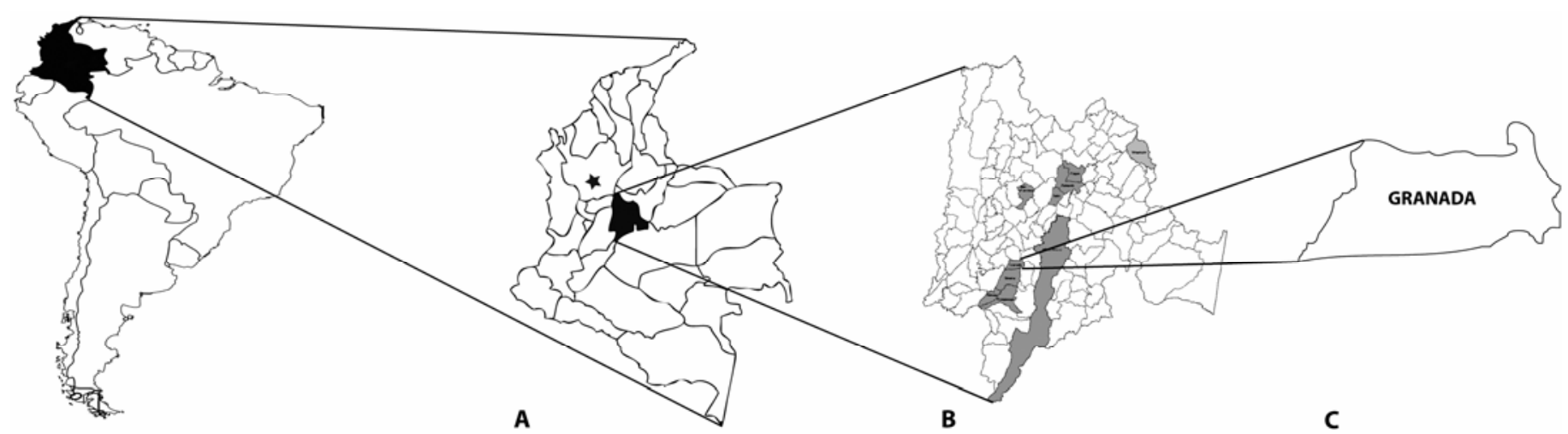

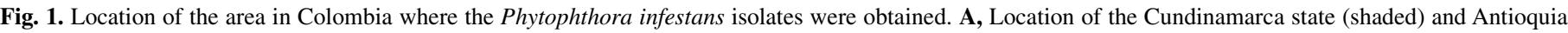

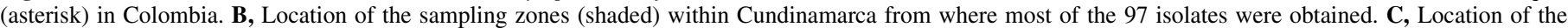
fields near the sampling site where the A2 mating type isolate was detected.

TABLE 1. Phytophthora infestans isolates used in this study

\begin{tabular}{|c|c|c|c|c|}
\hline Host & Location $^{\mathrm{a}}$ & Isolate ID & Mating type & Mitochondrial DNA \\
\hline \multirow[t]{2}{*}{ Solanum tuberosum } & Zipaquirá & 10111021104110511061101210221032104210521062 & & \\
\hline & & 10161026103610461056101710271047105710671077 & A1 & IIa \\
\hline \multirow[t]{2}{*}{ S. tuberosum } & Cogua & 10131023103310431053106310731014102410341044 & & \\
\hline & & 10541064107410151025103510451055 & A1 & IIa \\
\hline S. tuberosum & Granada & 101810281038104810581068107810881098 & A1 & IIa \\
\hline Physalis peruviana & Granada & 401140144024403440444054406440744094 & A1 & IIa \\
\hline P. peruviana & Granada & 4084 & $\mathrm{~A} 2$ & Ia \\
\hline P. peruviana & San Francisco & 4012402240234013 & A1 & IIa \\
\hline S. lycopersicum & Tabio & 301130213031 & A1 & IIa \\
\hline S. lycopersicum & Villapinzón & 30123022 & A1 & IIa \\
\hline S. lycopersicum & Fusagasugá & 301330233033 & A1 & IIa \\
\hline S. lycopersicum & Bogotá & 301430243034 & A1 & IIa \\
\hline S. lycopersicum & Tibacuy & 3015302530353045 & A1 & IIa \\
\hline S. betaceum & Rionegro & 6011602160316041 & A1 & IIa \\
\hline S. betaceum & Granada & 601260226032 & A1 & IIa \\
\hline S. quitoense & Rionegro & 50115021503150415051 & A1 & IIa \\
\hline S. phureja & Cogua & 201120212031204120512061 & A1 & IIa \\
\hline
\end{tabular}

a All locations are in Cundinamarca state except for Rionegro (Antioquia State). 
isolations from nonsporulating lesions, the lesion was placed between two potato slices and incubated in a humid chamber for 4 days at $18^{\circ} \mathrm{C}$. When sporulation became evident under the light microscope, sporangia were transferred to rye agar as previously described (19).

Morphological characterization. Using a light microscope (at $400 \times$ ), the sporangial width and length of each isolate were determined. Sporangia were obtained by flooding 8-day-old cultures on rye agar with water. The width and length of 10 sporangia per isolate were obtained to calculate an average. Other morphological characteristics, including the shape of sporangia, ramification of the sporangiophores, and presence of papillae, were recorded (10).

DNA extraction. Isolates were grown for 8 to 10 days at $18^{\circ} \mathrm{C}$ in clear pea broth that was prepared by autoclaving $120 \mathrm{~g}$ of fresh or frozen peas in 1 liter of water. The peas were removed and the broth autoclaved a second time prior to use. The mycelium was filtered, lyophilized, and ground with a mortar and pestle. DNA was extracted according to the method of Ordoñez (32).

Sequencing of the internal transcribed spacer region. The internal transcribed spacer (ITS) of the ribosomal (r)DNA of all $P$. infestans isolates was amplified using polymerase chain reaction (PCR) according to the methodology described by Cooke et al. (6). Amplifications were conducted in 25- $\mu$ l reaction volumes. Each reaction tube contained $1 \times$ PCR buffer, $0.2 \mathrm{mM}$ dNTP (each), $1 \mathrm{mM} \mathrm{MgCl} 2,0.2 \mathrm{mM}$ forward and reverse primers, and $0.2 \mu \mathrm{l}$ of $\mathrm{Taq}(5 \mathrm{U} / \mathrm{ml})$. The PCR conditions were as follows: 1 cycle at $96^{\circ} \mathrm{C}$ for $2 \mathrm{~min}$ and 35 cycles of $96^{\circ} \mathrm{C}$ for $1 \mathrm{~min}, 55^{\circ} \mathrm{C}$ for $1 \mathrm{~min}$, and $72^{\circ} \mathrm{C}$ for $2 \mathrm{~min}$. A final extension at $72^{\circ} \mathrm{C}$ for 10 min was done at the end of the amplification. The ITS primers ITS 5 (5'-GGAAGTAAAAGTCGTAACAAGG) and ITS 4 (5'TCCTCCGCTTATTGATATGC) amplified the ITS region I between the 18S and 5.8S rDNAs (39). All the $P$. infestans isolates yielded a 914-bp product. This product was then sequenced and sequences were compared with GenBank databases using Blastn. Finally, all sequences were aligned (using the software CLC Free Workbench, CLCBio, Cambridge, MA).

Mating type. Mating type was determined according to the methodology described by Forbes et al. (12). Each unknown Colombian isolate was paired on agar with a known A2 mating type strain (US940480) and each was also paired with a known A1 mating type strain (US940494). The presence of antheridia and oogonia where the two strains intersected indicated that the strains were of opposite mating type. Each assay was done three times. Each isolate that produced gametangia in the presence of the A1 tester was mating type A2, and each isolate that produced gametangia in the presence of the A2 tester was mating type A1. Additionally, using the same methodology, the Colombian isolate that showed the A2 mating type (see Results) was crossed with Colombian strains of mating type A1 isolated from potato $(n=5)$ and cape gooseberry $(n=5)$. In each cross, the number of oospores in an area of $11 \mathrm{~cm}^{2}$ was recorded and data were subjected to a $t$ test. Additionally, each Colombian isolate in pure culture was examined for autofertility by microscope observation of the culture.

Mitochondrial DNA haplotypes. The $P$. infestans collection was analyzed for mitochondrial haplotypes using the following primer pairs for specific mitochondrial DNA regions: P2 (P2F: 5'TTCCCTTTGTCCTCTACCGAT-3' and P2R: 5'-TTACGGCGGTTTAGCACATACA-3') and P4 (P4F: 5'-TGGTCATCCAGAGGTTTATGTT-3' and P4R: 5'-CCGATACCGATACCAGCACCAA-3') (21). PCR was carried out as follows for all primer combinations in a final volume of $25 \mu \mathrm{l}$ : $1 \times$ PCR buffer, $0.5 \mathrm{mM}$ dNTPs (each), $2.5 \mathrm{mM} \mathrm{MgCl}, 0.2 \mathrm{mM}$ each primer, and $0.2 \mu \mathrm{l}$ of Taq DNA polymerase $(5 \mathrm{U} / \mu \mathrm{l})$. The PCR conditions were 1 cycle of $94^{\circ} \mathrm{C}$ for $4 \mathrm{~min}$ and 35 cycles of $94^{\circ} \mathrm{C}$ for $60 \mathrm{~s}, 60^{\circ} \mathrm{C}$ for $45 \mathrm{~s}$, and $72^{\circ} \mathrm{C}$ for $120 \mathrm{~s}$. Amplified DNA ( $\left.4 \mu \mathrm{l}\right)$ was digested with the restriction enzyme $M s p \mathrm{I}(\mathrm{P} 2)$ and $4 \mu \mathrm{l}$ was digested with EcoRI
(P4), each in a $20-\mu l$ volume at $37^{\circ} \mathrm{C}(21)$. The resulting restriction fragments were separated on $2 \%$ agarose gels and visualized by staining with ethidium bromide (21).

Microsatellite analyses. Isolates were also evaluated with two primers selected from those reported by Lees et al. (25). Primer pairs used in this study were 4B (4BF 5'-AAAATAAAGCCTTTGGTTCA and 4BR 5'-GCAAGCGAGGTTTGTAGATT) and D13 (D13F 5'-TCGCCCCTGCTCACTC and D13R 5'-GCTCGAATTCATTTTACAGA). Amplifications were conducted in $25-\mu \mathrm{l}$ reaction volumes. Each reaction tube contained $1 \times$ PCR buffer; $0.2 \mathrm{mM}$ (each) of dNTPs, $1 \mathrm{mM} \mathrm{MgCl}, 0.2 \mathrm{mM}$ each forward and reverse primers, and $0.2 \mu \mathrm{l}$ of $\mathrm{Taq}(5 \mathrm{U} / \mathrm{ml})$. The thermal cycling parameters were initial denaturation at $94^{\circ} \mathrm{C}$ for 4 min followed by 35 cycles consisting of denaturation at $94^{\circ} \mathrm{C}$ for $1 \mathrm{~min}$, annealing at $40^{\circ} \mathrm{C}$ for $45 \mathrm{~s}$, and extension at $72^{\circ} \mathrm{C}$ for $2 \mathrm{~min}$. A final extension at $72^{\circ} \mathrm{C}$ for $7 \mathrm{~min}$ was done at the end of the amplification.

Aggressiveness on alternate host. Differential aggressiveness for isolates from potato (50 isolates) and from cape gooseberry (14 isolates) was tested in a cross-inoculation experiment. This experiment used a detached leaf assay on fully expanded leaves from 6-week-old greenhouse-grown plants of each host as described in previous studies $(15,33,38)$. Each isolate was evaluated on the host from which it was isolated (host of origin) and from the other host (alternate host). A susceptible cultivar of potato (Tocarreña) and a susceptible cultivar of cape gooseberry (Ecotipo Colombia) were used. For each strain, a suspension of 150,000 sporangia/ml was used. Sporangia were obtained from 8 -day-old cultures in rye agar. Sporangia were removed by scraping the flooded mycelium. The concentration of sporangia was measured using a Neubauer Chamber. Each suspension was incubated at $4^{\circ} \mathrm{C}$ for $2 \mathrm{~h}$ to induce zoospore liberation. Then, a drop $(10 \mu \mathrm{l})$ of the suspension was placed on each of three leaves of each host. Leaves were treated with $10 \mu \mathrm{l}$ of sterile distilled water as negative controls. Each leaf was placed in a humid chamber at $18^{\circ} \mathrm{C}$. Beginning at the third day of incubation, the lesion area was measured using Image $\mathbf{J}$ software (available online by NIH). If the lesion area produced by an isolate on the alternate host was greater than $50 \%$ of that on the host of origin, it was considered that the isolate had no specificity to its original host.

The significance of the interaction between isolates and hosts was tested with analysis of variance (ANOVA). Each plantpathogen combination was represented by three leaves for each variable under study, with each leaf in a separate petri dish. The petri dish was considered the experimental unit and the mean of three leaves as the basic unit for analysis. The whole experiment was repeated three times. The sources of variance analyzed were the (inoculated) host (potato or cape gooseberry), the original host of the isolate (potato or cape gooseberry), and the combination original host of the isolate-inoculated host.

The Shapiro-Wilk test was performed to test normality of data. If necessary, data were ln-transformed. Data were analyzed using a linear model and means were compared with the Tukey test $(\alpha=$ 0.05 ). All analyses were performed using the SPSS software (Statistical Product and Service Solutions, Chicago).

Isozyme electrophoresis and RG57 DNA fingerprints. Isozyme patterns and restriction fragment length polymorphism (RFLP) fingerprints were obtained for all 64 isolates collected from potato and cape gooseberry in order to further understand the distribution of the pathogen diversity among these two hosts. Isozyme electrophoresis for the enzyme glucose-6-phosphate isomerase (GPI) was carried out on cellulose-acetate gels as described by Goodwin et al. (17). RFLP fingerprints were obtained as described by Goodwin et al. (20).

\section{RESULTS}

Sampling and isolation of the pathogen. The sampling in Cundinamarca and Antioquia states in 2006 yielded a collection 
of 97 isolates comprising 50 from potato, 14 from cape gooseberry, 15 from tomato, 7 from tree tomato, 6 from yellow potato, and 5 from nanjarilla (or lulo) (Table 1). The number of collected isolates was directly correlated with the areas cultivated with each plant species in Cundinamarca and Antioquia. Hence, the predominance of isolates from potato is due to the extensive cultivation of this crop in the state of Cundinamarca, the most important producer of potato in Colombia.

All isolates fit the morphological description of $P$. infestans with deciduous and semipapillate sporangia (10). Sporangia had a mean length of $39.4 \pm 1.1 \mu \mathrm{m}$ and a mean width of $26.1 \pm 1.9 \mu \mathrm{m}$, falling within the range reported for P. infestans (10).

Sequencing of ITS region. The rDNA ITS1 characterization also is consistent with the hypothesis that all isolates are $P$. infestans sensu lato. In the analysis using Blastn, all sequences showed at least $97 \%$ similarity (and $e$ values of 0 ) to sequences in the databases reported as $P$. infestans. However, we are aware that all species belonging to clade 1 (6) have very similar ITS sequences, and ITS sequence alone cannot identify individuals in clade 1 to species unambiguously.

The assembled sequences (GenBank accession nos. EF173467EF173476, EU200238-EU200253, EU200255-EU200282, EU100284-EU200322, and EU216567-EU216570) were aligned to obtain a general consensus sequence of the 97 isolates. Most (91 of 97) of the sequences showed at least $99 \%$ similarity to the consensus sequence. The additional six isolates were at least $97 \%$ similar to the consensus sequence.

Mating type. Of the 97 isolates, 96 were mating type A1 because they formed gametangia structures only in response to the A2 tester strain, US940480. The remaining isolate (4084, isolated from cape gooseberry) was mating type A2 because it formed oospores when crossed with the A1 reference strain US940494. Isolates never produced oospores when grown in pure culture and it is possible that they do not display mechanisms of autofertility, at least under laboratory conditions.

Upon detection of the single A2 strain in Cundinamarca state, we sampled again to determine the frequency of appearance or the distribution of A2 strains in Cundinamarca state (Fig. 1C). This sample resulted in 100 strains that were assessed for mating type only; however, all of the isolates in this sample were also A1.

In an additional experiment, isolate 4084 (mating type A2) was paired with 10 A1 Colombian isolates, 5 from potato (isolates $1064,1053,1035,1078$, and 1041) and 5 from cape gooseberry (isolates 4024, 4012, 4044, 4034, and 4094). These 10 isolates came from different localities in Cundinamarca. This experiment was conducted to determine whether isolates show a preference to mate with isolates coming from the same host or if mating is independent of host preference (or specificity). In all cases, sexual structures and oospores were formed and there were no significant differences in the number of oospores produced as a function of host of origin. Interestingly, fewer oospores were produced when isolate 4084 was paired with the A1 tester strain than when paired with the Colombian isolates.

Mitochondrial haplotype. The $\mathrm{P} 4$ and $\mathrm{P} 2$ regions of mitochondrial DNA were amplified. All isolates produced a band of

TABLE 2. Analysis of variance of the size of the lesion area using a general linear model ${ }^{\mathrm{a}}$

\begin{tabular}{lrrcc}
\hline & \multicolumn{4}{c}{ Affected area } \\
\cline { 2 - 5 } Variable & df & MS & $F$ value & $P$ value \\
\hline Host (inoculated) $(\mathrm{I})$ & 1 & 145.66 & 6.71 & 0.0098 \\
Host of origin $(\mathrm{H})$ & 1 & 0.05 & 0.14 & 0.71 \\
$\mathrm{I} \times \mathrm{H}$ & 1 & 75.45 & 6.85 & $<0.0001$ \\
\hline
\end{tabular}

${ }^{a}$ Components of variance are the inoculated host (potato or cape gooseberry) in this assay, host of origin (potato or cape gooseberry) from which isolates were collected, and the inoculated host-host of origin combination; $\mathrm{df}=$ degrees of freedom, MS = mean square, and $R^{2}=0.995$.
964 bp for P4 and 1,070 bp for P2. An MspI digestion of P2 yielded either two fragments (for haplotype Ia, 720 and $350 \mathrm{bp}$ ) or three fragments (for haplotype IIa, 720, 203, and 147). An EcoRI digestion of $\mathrm{P} 4$ yielded either three fragments (for haplotype Ia, 394, 361, and 209 bp) or two fragments (for haplotype IIa, 603 and $361 \mathrm{bp})$. Most of the isolates $(n=96)$ had mitochondrial haplotype IIa, whereas one (the A2 isolate, 4084) had mitochondrial haplotype Ia (Table 1).

Microsatellite analyses. Although primers were selected based on previous reports that showed that these primers could detect several alleles and high levels of gene diversity (25), no polymorphisms were observed among the 97 Colombian isolates when assayed with the two microsatellite primers.

Aggressiveness on alternate host. We compared the aggressiveness of the isolates from potato $(n=50)$ and from cape gooseberry $(n=14)$ on their original hosts and on the alternate host. Aggressiveness was determined from measurements of lesion area. In general, the results from the cross-inoculations showed a significant difference for the interaction of interest (ANOVA analysis) (Table 2; Fig. 2) and a considerable level of host preference. These results indicated that isolates from cape gooseberry and isolates from potato were more aggressive on their host of origin (Fig. 2).

None of the strains inoculated on the alternate host produced a lesion that was greater than $50 \%$ the lesion size on the original host. In fact, most of the isolates (57 of 64) did not cause lesions on the alternate host, even when observed for a total of at least 21 days (cape gooseberry) or 15 days (potato). All 14 isolates from cape gooseberry produced large sporulating lesions that completely degraded the leaf within 21 days. However, only 3 of these 14 isolates from cape gooseberry $(4011,4024$, and 4074) generated necrotic lesions on potato, and none of these lesions was as large as $50 \%$ the size on the host of origin (cape gooseberry). Some lesions showed only mycelial growth and an absence of sporulation. These isolates came from two different geographic localities: 4011 was from San Raimundo whereas 4024 and 4074 were from Granada. All 50 isolates from potato produced large lesions on potato and the inoculated tissue was completely degraded after 15 days. Only 4 of the 50 isolates from potato caused lesions on cape gooseberry. Of the four strains that did produce small lesions on cape gooseberry, two (1017 and 1047) were collected from Zipaquirá and two (1013 and 1053) from Cogua (Table 1).

Because isolate 4084 (isolated from cape gooseberry) showed the typical isozyme genotype, mitochondrial DNA haplotype, RG57 fingerprint, and mating type of the US-8 clonal lineage,

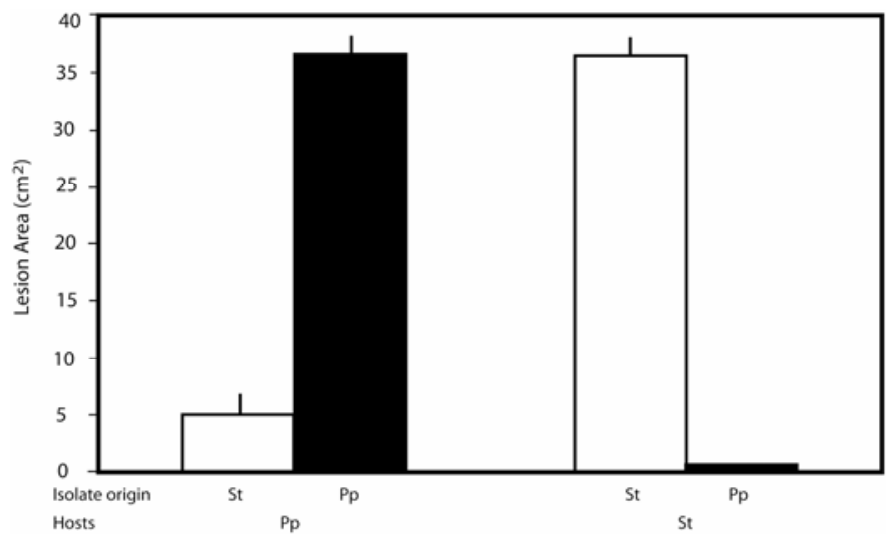

Fig. 2. Average lesion diameter of isolates of Phytophthora infestans on potato or on cape gooseberry. The "isolate origin" indicates the host from which the isolate was originally collected and "Host" indicates the species which was inoculated with a particular isolate. The hosts were Pp: Physalis peruviana and St: Solanum tuberosum. Error bars indicate \pm standard error of the means. 
which is a potato isolate (see results below), we tested its virulence on cvs. Kennebec (potato) and Sunrise (tomato). Interestingly, this isolate produced lesions on Kennebec and Sunrise that were $90 \%$ the size of those on cape gooseberry at 7 days after inoculation. However, on the standard test potato cv. Tocarreña, it failed to produce lesions that were larger than $50 \%$ of those on cape gooseberry. We also tested virulence of other cape gooseberry isolates (4033, 4074, 4022, 4012, 4054, 4023, 4011, 4013, 4094, and 4039) on Kennebec and Sunrise. Interestingly, these isolates produced lesions on Kennebec and Sunrise but the lesion sizes on Kennebec averaged $70 \%$ of the lesion size on cape gooseberry. On Sunrise, the lesion sizes averaged $45 \%$ of those produced on cape gooseberry 8 days after inoculations.

Isozyme profiling and RG57 DNA fingerprints. Isolates collected from potato and cape gooseberry were additionally analyzed by RFLP fingerprint and isozyme genotype (64 isolates). The cellulose acetate technique identified 63 isolates as 100/100 for GPI (with isolate 4084 being 122/111/100) and 62 isolates as 100/100 for peptidase (PEP), with isolates 1022 and 4012 being 92/100 (using the cellulose acetate technique, genotypes 100/100 and 96/100 for PEP are not distinguishable). All but three isolates had the same RFLP fingerprint, with isolate 1045 differing by a single band and isolates 1017 and 4012 differing by the same two bands. Using mating type and all molecular markers, we determined that the most commonly occurring lineage (59 of 64 isolates) was EC-1, and was found on both hosts (potato and cape gooseberry). This dominant Colombian clonal lineage (Table 3) differs from the US-1 in two RFLP loci, two allozyme loci, and mitochondrial haplotype.

There were a few other genotypes. The most different was represented by isolate 4084, which had the RG57 fingerprint, mating type, and isozyme pattern typical of the US-8 clonal lineage. Isolates 1022 and 4012 had the same RG57 fingerprint, mating type, and mitochondrial haplotype as EC-1 but had a different pattern for PEP. Isolate 1017 differed from EC-1 by two RFLP loci. Isolate 1045 differed from the EC-1 at one RFLP locus. Based on previous practice $(13,16,18)$, clonal lineages were determined by DNA fingerprint, mitochondrial haplotype, mating type, and isozyme patterns. Isolates that differed from the dominant lineage in only one RFLP band were considered to be a derivative of that lineage.

The dominant genotype on both potato and cape gooseberry was EC-1. This lineage accounted for 47 of 50 isolates on potato and 12 of 14 isolates on cape gooseberry. On potato, the other lineages were $\mathrm{CO}-1, \mathrm{CO}-2$, and EC1-1. On cape gooseberry, the other lineages were CO-1 and US-8 (Table 3).

\section{DISCUSSION}

This study revealed three important aspects of the $P$. infestans population in Colombia. First, we found one individual of the A2 mating type, which is the first report of this mating type in Colombia. Second, we found that the population is generally highly clonal-dominated by a single lineage. Third, we found host adaptation (for cape gooseberry or for potato) within that lineage.

We are certain that all isolates were $P$. infestans for the following reasons. The morphological characteristics fit $P$. infestans. The fingerprints obtained with RG57 had been reported previously or had a similar number of alleles as reported for other $P$. infestans isolates (19). The allozyme alleles are characteristic of $P$. infestans and the ITS sequences were all at least $97 \%$ identical to $P$. infestans. The similarity of ITS regions among strains of Phytophthora spp. is currently under study. Originally, it may have been believed that individuals in clade 1c had little diversity in the ITS region. For example, Kroon et al. (23) state: "For $P$. infestans and the closely related species $P$. mirabilis, $P$. ipomoeae, $P$. phaseoli, and $P$. andina, which comprise clade $1 \mathrm{c}$ in our analysis, ITS-sequence similarity was very high (99.9\%)." However, Kroon et al. (23) had only one strain per species. We had many more individuals in our study and the intraspecific similarity could be higher than reported by Kroon et al. (23). When we submitted our six more divergent (from the consensus sequence) sequences to GenBank, we obtained similarities of at least $97 \%$ with sequences reported as $P$. infestans or species belonging to clade1 from different hosts and origins (for example, accession numbers AJ854293.1 or AY829469.1). Also, when we compared $49 P$. infestans sequences in GenBank with our consensus sequence, similarities ranged from 89.6 to $100 \%$. The ITS sequences from other Phytophthora spp. in clade 1c ranged from 83 to $100 \%$ similarity to those of $P$. infestans.

Discovery of an individual (isolate 4084) of A2 mating type is potentially very important. It probably represents an introduction of $P$. infestans into Colombia (probably from the United States), and it also represents the potential for sexual reproduction of $P$. infestans in Colombia. During the time of our collection, this genotype was obviously not common, being detected only once (on cape gooseberry), even after a more intensive sampling near the site of the first detection. This single individual had all the characteristics of the US-8 lineage (18), which has been reported in Mexico, the United States, and Canada. We were initially surprised that it had low pathogenicity to potato cv. Tocarreña; however, testing on North American cv. Kennebec revealed that it was highly pathogenic on this cultivar. Because this isolate could produce oospores when paired with other isolates from cape gooseberry, we suspect that premating isolation is unlikely to preclude sexual reproduction in Colombia. It will be instructive to determine whether the oospores produced can give rise to viable and fit progeny. In previous assessments of sexual reproduction using other parents, most progeny have been less fit than either parent (28).

The Colombian $P$. infestans population was characterized by very low diversity. We found no evidence of sexual reproduction.

TABLE 3. Genetic characterization of populations of Phytophthora infestans isolated from potato (Solanum tuberosum) and cape gooseberry (Physalis peruviana) $(64 \text { isolates })^{\mathrm{a}}$

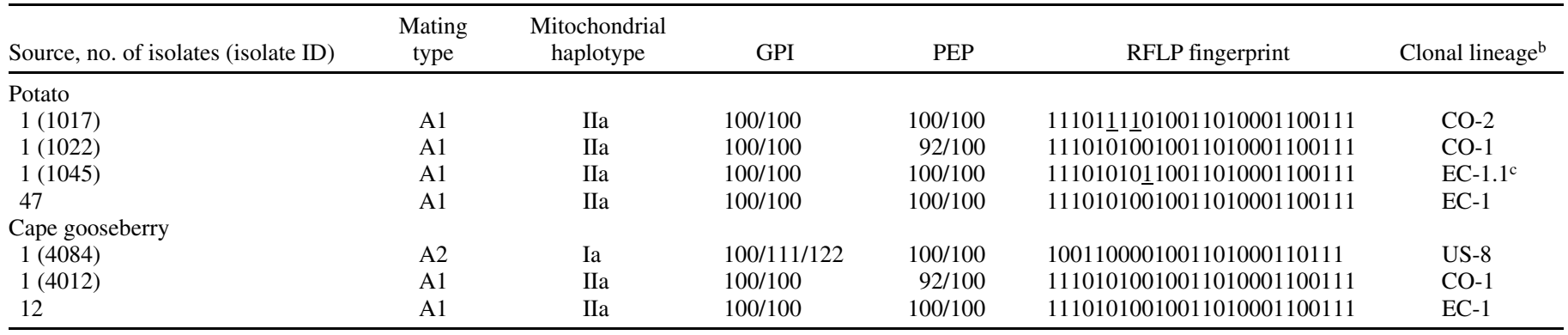

${ }^{a}$ GPI = glucose-6-phosphate isomerase, $\mathrm{PEP}=$ peptidase, and RFLP = restriction fragment length polymorphism.

${ }^{\mathrm{b}}$ Clonal lineage to which isolates belong according to previous studies $(13,16,18)$.

${ }^{c}$ Differs from EC-1 genotype by one locus (underlined). 
The predominant genotype characterized in our study had a multilocus genotype that we identified as EC- 1 and only three isolates deviated from the predominant RFLP pattern with variation at one or two loci. In previous studies, such minor changes were attributed to mutation or mitotic recombination within clonal lineages (12). We adopted the practice used by Forbes et al. (12) to indicate that isolates that differ by only a single RFLP allele are derivatives of the same lineage, and we therefore identified one isolate as being in EC-1.1. Our results are consistent with an earlier report in which Colombian isolates from Antioquia collected in the 1990s did not have the 86 allele for Gpi or the 92 allele for Pep (which are characteristic of US-1) and also with a report that some isolates from Colombia were clonal lineage EC-1 (12).

We found evidence for host preference (potato or cape gooseberry) within the EC-1 population. Either quantitative aggressiveness $(15,33)$, or resistance gene virulence could explain the host specificity we observed. Regardless of the mechanism, host specificity may have important consequences for disease management. Our results could lead us to suggest that farmers should not be concerned with epidemics on nearby (or even sometimes in the same field) alternate hosts (particularly cape gooseberry and potato). However, it would be premature to suggest that one plant does not produce inoculum for the other before more studies are conducted to evaluate different components of aggressiveness in the field (24). In many other reports of host preference for $P$. infestans, preference for a host is associated with a particular lineage $(4,14,20,22,24,26,33)$ and there are typically very few lineages in the agroecosystem. The adapted lineage rarely causes severe disease on other hosts. The situation in Colombia is similar to that reported for Uganda and Kenya (38), in which there was host preference within a single lineage. We believe that the pathogenicity to cape gooseberry may have evolved within the EC-1 lineage from potato pathogenicity. The main supporting argument for this is that, in Cundinamarca, potato crops have been grown traditionally, whereas cape gooseberry is a more recently domesticated and introduced crop. Cape gooseberry is native to Peru $(29,30)$ but has been grown as a commercial crop in Colombia only for 30 to 40 years. Therefore, we recommend that, although isolates from each host showed reduced aggressiveness on the alternate host, integrated pest management efforts for both potato and cape gooseberry should be coordinated. Adaptation to a new host is not always associated with reduced fitness in the original host (24) and, until more components of aggressiveness (infection efficiency and sporulation, among others) are determined, caution must be taken in the control management efforts.

This study is part of our continuing effort to understand the population structure of $P$. infestans in Colombia. Knowledge of pathogen population structure and dynamics is useful in determining the most appropriate integrated management strategies. We will be particularly alert for the occurrence of sexual reproduction.

\section{ACKNOWLEDGMENTS}

We thank La Facultad de Ciencias of the Universidad de los Andes for funding and L. Granke for help in editing the manuscript.

\section{LITERATURE CITED}

1. Abad, Z. G., and Abad, J. A. 1997. Another look at the origin of late blight of potatoes, tomatoes and pear melon in the Andes of South America. Plant Dis. 81:682-688.

2. Adler, N. E., Chacón, G., Flier, W. G., and Forbes, G. A. 2002. The Andean fruit crop, pear melon (Solanum muricatum) is a common host for A1 and A2 strains of Phytophthora infestans in Ecuador. Plant Pathol. 51:802.

3. Adler, N. E., Erselius, L. J., Chacón, M. G., Flier, W. G., Ordoñez, M. E., Kroon, L. P. N. M.. and Forbes, G. A. 2004. Genetic diversity of
Phytophthora infestans sensu lato in Ecuador provides new insight into the origin of this important plant pathogen. Phytopathology 94: 154-162.

4. Brommonschenkel, S. H. 1988. Pathogenicity, compatibility, cytogenetics and isoenzyme patterns of Brazilian isolates of Phytophthora infestans (Mont.) de Bary. Universidade Federal de Viçosa, Viçosa.

5. Colon, L. T., and Budding, D. J. 1988. Resistance to late blight (Phytophthora infestans) in ten wild Solanum species. Euphytica S:77-86.

6. Cooke, D. E. L., Drenth, A., Duncan, J. M., Wagels, G., and Brasier, C. M. 2000. A molecular phylogeny of Phytophthora and related oomycetes. Fungal Genet. Biol. 30:17-32.

7. Corporación Colombia Internacional, C. 2000. Inteligencia de mercados: perfil del producto Uchuva. Pages 1-12 in: M. Ministerio de Agricultura y Desarrollo Rural, ed. Perfil de producto, vol. 13.

8. Chardon, C. E. 1928. Contribución al estudio de la flora micológica de Colombia. Bol. Real Soc. Esp. Hist. Nat. 28:111-124.

9. Chardon, C. E., and Toro, R. A. 1930. Mycological explorations of Colombia. J. Dep. Agric. Porto Rico 14:195-357.

10. Erwin, D. C., and Ribeiro, O. K. 1996. Phytophthora Diseases Worldwide. American Phytopathological Society Press, St. Paul, MN.

11. FAO. 2007. FAO agricultural statistics. [Online.]

12. Forbes, G. A., Escobar, X. C., Ayala, C. C., Revelo, J., Ordonez, M. E., Fry, B. A., Doucett, K., and Fry, W. E. 1997. Population genetic structure of Phytophthora infestans in Ecuador. Phytopathology 87:375-380.

13. Forbes, G. A., Goodwin, S. B., Drenth, A., Oyarzun, P., Ordonez, M. E., and Fry, W. E. 1998. A global marker database for Phytophthora infestans. Plant Dis. 82:811-818.

14. Fry, W. E., Drenth, A., Spielman, L. J., Mantel, B. C., and Davidse, L. C. 1991. Population genetic structure of Phytophthora infestans in the Netherlands. Phytopathology 81:1330-1336.

15. Garry, G., Forbes, G. A., Salas, A., Santa Cruz, M., Perez, W. G., and Nelson, R. J. 2005. Genetic diversity and host differentiation among isolates of Phytophthora infestans from cultivated potato and wild solanaceous hosts in Peru. Plant Pathol. 54:740-748.

16. Gavino, P. D., and Fry, W. E. 2002. Diversity in and evidence for selection on the mitochondrial genome of Phytophthora infestans. Mycologia 94:781-793.

17. Goodwin, S. B., Cohen, B. A., Deahl, K. L., and Fry, W. E. 1994. Migration from northern Mexico as the probable cause of recent genetic changes in populations of Phytophthora infestans in the United States and Canada. Phytopathology 84:553-558.

18. Goodwin, S. B., Cohen, B. A., and Fry, W. E. 1994. Panglobal distribution of a single clonal lineage of the Irish potato famine fungus. Proc. Natl. Acad. Sci. USA 91:11591-11595.

19. Goodwin, S. B., Smart, C. D., Sandrock, R. W., Deahl, K. L., Punja, Z. K., and Fry, W. E. 1998. Genetic change within populations of Phytophthora infestans in the United States and Canada during 1994 to 1996: role of migration and recombination. Phytopathology 88:939-949.

20. Goodwin, S. B., Spielman, L. J., Matuszak, J. M., Bergeron, S. N., and Fry, W. E. 1992. Clonal diversity and genetic differentiation of Phytophthora infestans populations in Northern and Central Mexico. Phytopathology 82:955-961.

21. Griffith, G. W., and Shaw, D. S. 1998. Polymorphisms in Phytophthora infestans: four mitochondrial haplotypes are detected after PCR amplification of DNA from pure cultures or from host lesions. Appl. Environ. Microbiol. 64:4007-4014.

22. Koh, Y. J., Goodwin, S. B., Dyer, A. T., Cohen, B. A., Ogoshi, A., Sato, N., and Fry, W. E. 1994. Migrations and displacements of Phytophthora infestans populations in East Asian countries. Phytopathology 84:922927.

23. Kroon, L. P. N. M., Bakker, F. T., van den Bosch, G. B. M., Bonants, P. J. M., and Flier, W. G. 2004. Phylogenetic analysis of Phytophthora species based on mitochondrial and nuclear DNA sequences. Fungal Genet. Biol. 41:766-782.

24. Lebreton, L., Lucas, J.-M., and Andrivon, D. 1999. Aggressiveness and competitive fitness of Phytophthora infestans isolates from potato and tomato in France. Phytopathology 89:679-686.

25. Lees, A. K., Wattier, R., Shaw, D. S., Sullivan, L., Williams, N. A., and Cooke, D. E. L. 2006. Novel microsatellite markers for the analysis of Phytophthora infestans populations. Plant Pathol. 55:311-319.

26. Legard, D. E., and Fry, W. E. 1996. Evaluation of field experiments by direct allozyme analysis of late blight lesions caused by Phytophthora infestans. Mycologia 88:608-612.

27. Leung, H., Nelson, R. J., and Leach, J. E. 1993. Population structure of plant pathogenic fungi and bacteria. Adv. Plant Pathol. 10:157-205.

28. Mayton, H., Smart, C. D., Moravec, B. C., Mizubuti, E. S. G., Muldoon, A. E., and Fry, W. E. 2000. Oospore survival and pathogenicity of single oospore recombinant progeny from a cross involving US-17 and US-8 genotypes of Phytophthora infestans. Plant Dis. 84:1190-1196.

29. Morton, J. F. 1987. Cape gooseberry. Pages 430-434 in: Fruits of Warm 
Climates. J. F. Morton, Miami, FL.

30. Office of International Affairs. 1989. Goldenberry-cape gooseberry. Pages 240-251 in: Lost Crops of the Incas: Little-Known Plants of the Andes with Promise for Worldwide Cultivation. Office of International Affairs.

31. Oliva, R. F., Erselius, L. J., Adler, N. E., and Forbes, G. A. 2002. Potential of sexual reproduction among host-adapted populations of Phytophthora infestans sensu lato in Ecuador. Plant Pathol. 51:710-719.

32. Ordoñez, M. E., Hohl, H. R., Velasco, J. A., Ramon, M. P., Oyarzun, P. J., Smart, C. D., Fry, W. E., Forbes, G. A., and Erselius, L. J. 2000. A novel population of Phytophthora, similar to P. infestans, attacks wild Solanum species in Ecuador. Phytopathology 90:197-202.

33. Oyarzun, P. J., Pozo, A., Ordoñez, M. E., Doucett, K., and Forbes, G. A. 1998. Host specificity of Phytophthora infestans on tomato and potato in Ecuador. Phytopathology 88:265-271.

34. Perez, W. G., Gamboa, J. S., Falcon, Y. V., Coca, M., Raymundo, R. M., and Nelson, R. J. 2001. Genetic structure of Peruvian populations of Phytophthora infestans. Phytopathology 91:956-965.
35. Toro, R. A. 1927. Enfermedades y plagas de las plantas. Esc. Agric. Vet. Medellín Circ. No 4.

36. Turkensteen, L. J. 1978. Phytophthora infestans: three new hosts and a specialized form causing a foliar blight of Solanum muricatum in Peru. Plant Dis. Rep. 62:829.

37. Vargas, A. M., Correa, A., Lozano, D. C., González, A., Bernal, A. J., Restrepo, S., and Jiménez, P. 2007. First report of late blight caused by Phytophthora infestans on cape gooseberry (Physalis peruviana) in Colombia. Plant Dis. 91:464.

38. Vega-Sánchez, M. E., Erselius, L. J., Rodriguez, A. M., Bastidas, O., Hohl, H. R., Ojiambo, P. S., Mukalazi, J., Vermeulen, T., Fry, W. E., and Forbes, G. A. 2000. Host adaptation to potato and tomato within the US-1 clonal lineage of Phytophthora infestans in Uganda and Kenya. Plant Pathol. 49:531-539.

39. White, T. J., Bruns, T., Lee, S., and Taylor, J. 1990. Amplification and direct sequencing of fungal ribosomal RNA genes for phylogenetics. In: PCR Protocols. M. A. Innis, D. H. Gelfand, J. J. Sninsky, and T. J. White, eds. Academic Press, San Diego, CA. 